\title{
Study of Poisoning Cases Admitted in ICU of Western Regional Hospital.
}

Surya Bahadur Hamal Thakuri ${ }^{1}$, Suresh Thapa ${ }^{2}$, Madan Prasad Baral ${ }^{3}$, Buddhi Sagar Lamichhane ${ }^{4}$

${ }^{1}$ Department of Internal Medicine, Pokhara Academy of Health Sciences, Western Regional Hospital

${ }^{2}$ Department of Forensic Medicine, Pokhara Academy of Health Sciences, Western Regional Hospital

\section{Correspondence}

Dr. Surya Bahadur Hamal Thakuri

MD, Internal Medicine

Department of Internal Medicine

Pokhara Academy of Health Sciences

Western Regional Hospital

Email: drsuryahamal2000@gmail.com

Article received: July 282020

Article accepted: Dec 12020

\section{ABSTRACT}

Introduction: Acute poisoning, irrespective of the etiology, is a medical emergency which requires prompt diagnosis and treatment. Such cases require ICU set up for better management. Central level hospitals in Nepal have ICU facilities to manage such cases. Materials and Methods: Current study is a retrospective type hospital based study conducted in Western Regional Hospital, Pokhara. Data collected from ICU department of Hospital in a period of one year from 2073 Ashad 16 to 2074 Ashad 16. It was analyzed and presented. Results: In this study it is observed that total 90 cases admitted in ICU department of WRH in a period of one year. Female patients outnumbered the male patients. Age group of $10-20$ years is predominance in present study. Most of the patients were from Kaski district as the hospital belongs to Kaski district and one of the renowned tertiary care centers in the Gandaki province. Maximum number of patients consumed the OP compound. Outcome was better as out of 90 cases 80 were discharged and only 10 were died during the course of treatment. Conclusion: Early identification of the cause and type of poisoning, close monitoring and standard management, preferably in the ICU for at least a first few days, reduces the complication and improves the survival. The commonly available insecticides and rodenticides are the most common cause of acute poisoning . Keywords: ICU, poisoning, western regional hospital.

\section{INTRODUCTION}

Poisoning is a varied subject that involves a variety of chemical and pharmaceutical compounds in different combinations ${ }^{1}$.Poisoning or intoxication can be defined as the happening of harmful effects as a result from exposure to a foreign chemical or a xenobiotic ${ }^{2}$. Intensive care unit (ICU) treatment of the patient with poisoning needs rapid diagnosis and supportive care while providing specific antidotal treatment in some cases ${ }^{3,4,5}$. In developing countries, the poisoning has doubled during the past decades and causes a large number of fatal outcomes even 
Original Article

though Increased availability of ICU facilities ${ }^{6,7,8}$.

\section{MATERIALS AND METHODS:}

This study is a retrospective type hospital based study conducted in Western Regional Hospital, Pokhara. Data collected from ICU department of Hospital in a period of one year from 2073 Ashad 16 to 2074 Ashad 16. Various types of poisoning cases admitted in ICU were included. The number of cases admitted in that period was 90 cases. Data analysis was done according to need of the study focusing on demographic profiles.

\section{RESULTS}

In this study it is observed that total 90 cases admitted in ICU department of WRH in a period of one year. Female patients outnumbered the male patients which were 50 and 40 respectively (Figure1).

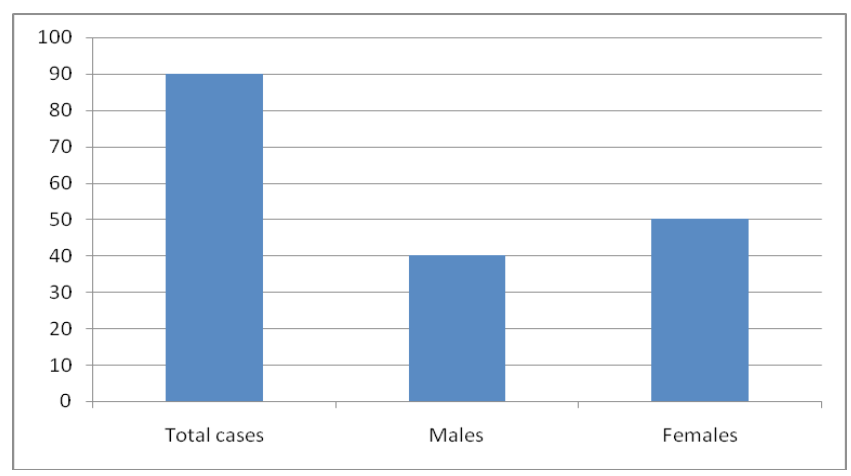

Figure 1: Sex wise distribution of cases

The age group of $10-20$ years is predominance in present study which is $41 \%$ of total cases.( Figure 2).

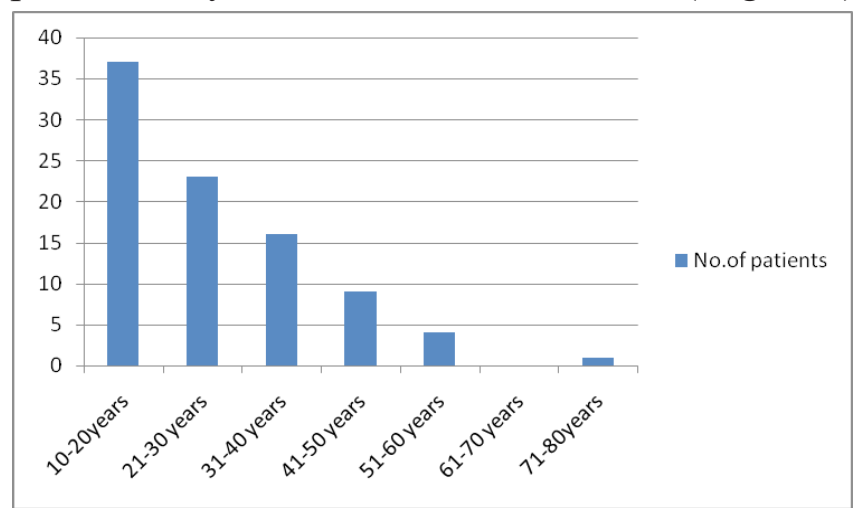

Figure 2: Age wise distribution of cases

Similarly most of the patients were from Kaski district as the hospital belongs to Kaski district and one of the renowned tertiary care centers in the Gandaki province
Medical Journal of Pokhara Academy of Health Sciences Vol. 3 Issue 2

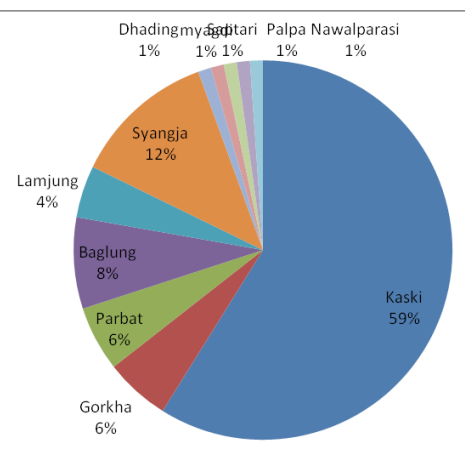

\section{Figure 3}

Various type of poisons were ingested by patients and admitted in ICU. Organo phosphorous compound poison (OP compound) was consumed by 39 cases which is the largest number in total 90 patient which were admitted in ICU by Poisoning. This was followed by Rodenticide poisoning which was 32 in number out of total 90 cases. Cypermethrin poisoning was the third in number which was 5 . Besides this various other poison were also consumed by patients including drugs as well (Figure 4).

Figure 4: Distribution of cases by types of poison

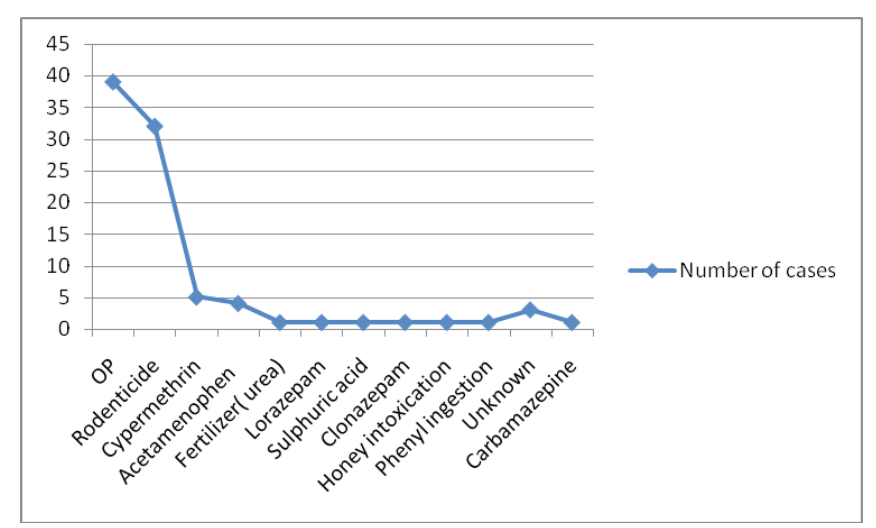

Regarding the outcome of patients discharged alive patients outnumbered the expired patient which is a good part of Hospital and departmental Management of Poisoning cases. This includes only 10 expired patients out of 90 patients where as alive discharged were 80 in number (Table 1).

Table 1: Outcome of patients

\begin{tabular}{|c|c|}
\hline No. of Patients & Outcome \\
\hline 10 & Expired (Dead) \\
\hline 80 & Discharged (Alive) \\
\hline
\end{tabular}




\section{DISCUSSION}

Admission of 90 cases of poisoning in the ICU of Western Regional Hospital over a period of one year emphasizes the seriousness of the problem of poisoning in this area. Acute poisoning is an important clinical emergency with a significant contribution to morbidity and mortality. Prompt diagnosis, treatment and prevention of complications are crucial in reducing the burden of poisoningrelated injury.

Our study analyzed the clinical profile, type of poison and outcome of poisoned patients admitted in the ICU of Western Regional Hospital during the study period. This study revealed that $50(55.56 \%)$ of our patients were females and $40(44.44 \%)$ of them were males ( Graph 1). The female to male ratio was $1.25: 1$. A similar study done in Pokhara on 98 patients showed this ratio to (1) be 1.18:1. ${ }^{12}$ In present study female patients who consumed the poisonous substance were more than the male patients ( Graph 1). This is just opposite(contrary) to the study done by Cairans, Nirmal and Tendon et.al in which they found number of male patients were more than that of female patients. ${ }^{9-11}$

The age group 10-20 years was the highest in number in our study( Graph 2). The highest age group was 2140 in a study conducted by P. V. Kishore et al at Manipal Teaching Hospital, Pokhara. ${ }^{12}$ In a study conducted by Khadka et $\mathrm{al}^{13}$ from Nepal and Gajri et $\mathrm{al}^{14}$ from India, the highest number of patients were from the 21-30 years age group. In general, the adolescent and middle-aged group is more prone to stress and thus, might be more vulnerable to suicidal poisoning.

The most common poison consumed in our study was the organophosphates, which was ingested by 39 patients $(43.33 \%)$. The next common poison was the rodenticides, which was consumed by 32 patients $(35.56 \%)$ ( Graph 4). In a similar study done in Nepal by Paudyal et al, organophosphates were the most common poisons consumed. ${ }^{15}$ Another study by Singh et al from South India reported agrochemical pesticides as the most common poisons. ${ }^{16}$ Our finding showed that the rodenticide poisoning is also common in our part of the world is supported by a study conducted in India by Gargi et al, which showed that $38.23 \%$ of the total poisoning cases were due to aluminium phosphide (a constituent in rodenticide). Siwach et al, in his study done in North India reported $67.8 \%$ of the total poisoning due to aluminiumphosphide. ${ }^{17}$

Organophosphorus compounds are a major cause of poisoning in developing world. In our study, it was the most common group of poisons responsible for poisoning. Since organophosphorus poisoning is very common in our part of the world, clinicians should follow standard guidelines for managing the patients with OP poisoning. Singh S provides an evidence based approach for managing OP poisoning. ${ }^{18}$

The findings of our study also suggest that there is a free availability of rat poisons in our region. Rodenticides can be of mainly three types, anticoagulants (super warfarins), phosphide containing and red squill containing.19 since rat poisoning is common in our region, there is need for developing standard guidelines for managing this poison.

Most of our patients (88.89\%) recovered from acute poisoning and were discharged. The mortality rate was $11.11 \%$ (10/90).( Table 5) In a similar study done by Gyenwali et al in Chitwan (Nepal), 87.3\% of the total patients survived the acute poisoning, and were discharged..$^{20}$ In a similar study conducted by Sharma $\mathrm{R}$ et al in North India, the mortality rate of acute poisoning was $8.31 \%$, which was similar to our study. ${ }^{21}$

\section{CONCLUSION}

A cute poisoning, irrespective of the etiology, is a medical emergency which requires prompt diagnosis and treatment. Early identification of the cause and type of poisoning, close monitoring and standard management, preferably in the ICU for at least a first few days, reduces the complication and improves the survival. The commonly available insecticides and rodenticides are the most common cause of acute poisoning. So, strict legislation to restrict the easy access to these poisons can certainly decrease the poison-related morbidity and mortality. 


\section{REFERENCES}

1. Lam SM, Lau ACW, and Yan WW. Over 8 years experience on severe acute poisoning requiring intensive care in Hong Kong, China. HumExpToxicol. 2010; 29:757 - 765.

2.Irwin SR, Rippe JM. Irwin and Rippe's Intensive Care Medicine. 7th ed. Lippincott Williams \& Wilkins, 2008, pp: 1433-55.

3. Greene SL, Dargan PI, Jones AL. Acute poisoning: understanding $90 \%$ ofcases in a nutshell. Postgrad Med J 2005; 81:204-16.

4.Alapat PM, Zimmerman JL. Toxicology in the critical care unit. Chest2008;133:1006-13

5.Mokhlesi B, Leikin JB, Murray P, Corbridge TC. Adult toxicology in critical care. Part II: specific poisonings. Chest 2003;123:897-922.

6.Eizadi-Mood N, Saghaei M, Jabalameli M (2007) Predicting outcomes inorganophosphate poisoning based on APACHE II and modified APACHE IIscores. Hum ExpToxicol 26: 573-578.

7.World Health Organization (1997) Guidelines for poison control. WHO incollaboration with UNEP and ILO.

8.Shadnia S, Esmaily H, Sasanian G, Pajoumand A, Hassanian-Moghaddam $\mathrm{H}$,

et al (2007) Pattern of acute poisoning in TehranIran in 2003. Hum ExpToxicol

26: 753-756.

9. Cairans FJ, Koelmeyer TD, Smeeton WM. Deaths from drugs and poisons. N Z Med J. 1982;96:10458.[PubMed]

10. Nimal S, Laxman K. Pattern of acute poisoning in a medical unit in central Srilanka. Forensic Sci Int. 1988;36:101-4. [PubMed]

11. Tendon SK, Qureshi GU, Pandey DN, Aggarwal A. A profile of poisoning cases admitted in S.N. Medical College and Hospital, Agra. J Forensic Med Toxicol. 1996;13:10-2.

12 Kishore P. V., Palaian S, Paudel R, Mishra D,
Ojha P, Alam K, et al. Pattern of poisoning cases in a teaching hospital in Western Nepal. Journal of Institute of Medicine. 2008; 30:26-34.

13 Khadka SB, Khadka SB. A study of poisoning cases in emergency Kathmandu Medical College Teaching Hospital. Kathmandu Univ Med J (KUMJ). 2005; 3(12): 388-91.

14 Gargi J, Rai H, Chanana A, Rai G, Sharma G, Bagga IJ. Current trend of poisoning-a hospital profile. J Indian Med Assoc. 2006; 104 (2):72-3, 94.

15 Paudyal BP. Poisoning: pattern and profile of admitted cases in a hospital in central Nepal. J Nep Med Assoc. 2005; 44:92-6.

16 Singh B, Unnikrishnan B. A profile of acute poisoning at Mangalore (South India). J Clin Forensic Med. 2006; 13(3):112-6. [Epub 2006 Mar 10].

17 Iwach SB, Gupta A. The profile of acute poisonings in Harayana-Rohtak Study. J Assoc Physicians India. 1995; 43 (11):756-9.

18 Singh S. Organophosphorous poisoning: an evidence based approach. MJAFI. 2004; 60:24.

19 Olson KR, eds. Poisoning and drug overdose. 3rd edition, Connecticut: Appleton and Lange, 1998

20 Gyenwali D, Vaidya A, Tiwari S, Khatiwada P, Lamsal DR, Giri S. Pesticide poisoning in Chitwan, Nepal: a descriptive epidemiological study. BMC Public Health (2017) 17:619.

21 Sharma R, Neelanjana, Rawat N, Panwar N. Mortality and morbidity associated with acute poisoning cases in north-east India: A retrospective study. J Family Med Prim Care. 2019; 8:206872. 